\title{
Conexões
}

Artigo Original

\section{Um olhar sobre os jogos escolares do Rio Grande do Norte: recortes da história da capoeira no estado}

\author{
Rayanne Medeiros da Silva ${ }^{1}$
} Allysson Carvalho de Araújo ${ }^{1}$

\section{RESUMO}

Falar sobre capoeira como prática esportiva é algo muito recente nos diferentes espaços, pois, tradicionalmente, ela recebe uma ênfase em sua vertente cultural do que propriamente como esporte e suas especificidades quando comparada a outras manifestações da cultura de movimento. Nesse sentido, apresentamos uma pesquisa piloto para registrar e compreender como a Capoeira foi historicamente constituída nos espaços estudantis, especificamente, nos Jogos Escolares do estado do Rio Grande do Norte. Nestes termos, o presente estudo caracteriza-se como uma pesquisa descritiva que faz uso de entrevistas e documentos para compreender o fenômeno estudado, utilizando como referências a oralidade e o acervo do Mestre Marcos. Identificamos que os Jogos Escolares Brasileiros disseminaram a Capoeira como esporte-competição a todo Brasil e influenciaram diretamente a introdução da Capoeira nos Jogos Escolares do Rio Grande do Norte.

Palavras-Chave: Capoeira. Educação física. História. Rede Cedes.

\footnotetext{
${ }^{1}$ Universidade Federal do Rio Grande do Norte

Submetido em: 10 ago. 2016

Aceito em: 14 dez. 2016

Contato: rayannemedeiross@ @otmail.com

Conexões: Educ. Fís., Esporte e Saúde, Campinas: SP, v. 15, n. 2, p. 129-141, abr./jun. 2017. ISSN: 1980-9030
} 


\section{A look at school games in Rio Grande do Norte: clippings of the history of capoeira in the state}

\section{ABstract}

The cultural aspects of Capoeira are usually emphasized over its sportive branch, which is very recent, especially compared with other expressions of the movement culture. In this respect, this research aims at registering and comprehending how Capoeira has been historically constituted in student contexts, especially the School Games of Rio Grande do Norte. This is a descriptive research that uses interviews and archive materials from the collection of Master Marcos in order to comprehend the studied phenomenon. We identified that the Brazilian School Games disseminated Capoeira as a competitive sport throughout the country and directly influenced the introduction of Capoeira in the School Games of Rio Grande do Norte.

Keywords: Capoeira. Physical education. History. Rede Cedes.

\section{Una mirada sobre los juegos escolares de Rio Grande do Norte: recortes de la historia de la capoeira en el estado}

\section{RESUMEN}

Hablar de la capoeira como deporte es algo reciente en distintos ambitos. Tradicionalmente es mas conocida por su importancia cultural que por ser un deporte con características específicas, en comparación con cualquier otra manifestación de la cultura del movimiento. Con lo anterior presentamos un estudio piloto para comprender historicamente como la capoeira fue creada, especificamente en los juegos escolares de Rio Grande del Norte. En consecuencia, el presente estudio se caracteriza por ser una investigación descriptiva la cual contiene en entrevistas y material de archivos de recuperación para dar una claridad más efeciente en el fenomeno estudiado. Según el maestro Marcos, la capoeira se introdujo como Juegos Escolares Brasileños, extendiendose después como una competencia deportiva en todo Brasil, teniendo una influencia de esto especificamente en Los juegos Escolares del Rio Grande del Norte.

Palabras Clave: Capoeira. Educación física. Historia. Rede Cedes. 


\section{INTRODUÇÃO}

Para pensar os processos históricos da capoeira, se faz necessário compreender alguns aspectos que conotam essa manifestação. Marcada pelo aprisionamento e nascida em um contexto socioeconômico que se utilizava da escravidão do negro, a capoeira surge como uma luta com anseio de liberdade (REGO, 1968). No entanto, atualmente ela pode vir a ser considerada como jogo, luta, expressão cultural e diversos outros sentidos atribuídos pelos diferentes sujeitos que a experienciam.

Falar sobre capoeira como prática esportiva é algo muito recente nos diferentes espaços, pois tradicionalmente ela recebe mais ênfase em sua perspectiva cultural do que propriamente como esporte e suas especificidades, quando comparada a outras manifestações da cultura de movimento, especialmente ao pensarmos nos espaços educacionais. Acreditamos que isso se dá pela própria construção histórica dessa vertente e seus desdobramentos desde sua gênese até aqui. Contudo, tem-se ampliado esse olhar sobre a capoeira e a prática competitiva dessa modalidade, que já é presente em alguns espaços.

Podemos destacar o cenário dos jogos escolares norte-rio-grandense, onde essa manifestação conquistou seu espaço e sua tradição vem sendo consolidada. Apesar disso, esse fenômeno destoa quando pensamos em um contexto mais amplo, e isso nos levou a tentar compreender como a capoeira, pouco considerada como prática esportiva adentra a esse lócus marcado pela esportivização no estado do Rio Grande do Norte.

Nesse sentido o objetivo geral da nossa pesquisa é registrar e compreender como a capoeira foi historicamente constituída nos espaços estudantis, especificamente, nos Jogos Escolares do estado do Rio Grande do Norte (JERNs).

Essa pesquisa é fruto dos estudos desenvolvidos pelo Centro de Desenvolvimento de Pesquisa em Políticas de Esporte e Lazer da Rede Cedes, no estado do Rio Grande do Norte, cujas ações englobam, também, a estruturação do Centro de Memória em Educação Física, Esporte e Lazer do RN, que tem como objetivo reconstruir, preservar e divulgar a memória do Esporte, Educação Física e Lazer no estado ([2008?]).

\section{Metodologia}

Para pensar em pesquisa e seu conceito, dialogaremos com a definição atribuída por Gil (2008, p. 45), ao afirmar que: 
Pode-se definir pesquisa como o processo formal e sistemático de desenvolvimento do método científico. O objetivo fundamental da pesquisa é descobrir respostas para problemas mediante o emprego de procedimentos científicos.

Neste sentindo, a pesquisa apresenta-se como sendo descritiva e este processo metodológico circundou uma abordagem qualitativa, intrinsecamente relacionada ao assunto a ser investigado. Como método, nos apropriamos da história oral para dar suporte à nossa investigação.

Por considerar que este método

permite lidar com aspectos histórico-sociológicos ao captar, através da visão de um indivíduo, o desenvolvimento cronológico do fenômeno em estudo, inserido no contexto mais amplo da sociedade; possui um caráter dinâmico pois permite resgatar os processos sociais que deram origem aos fenômenos estudados possibilitando também um acompanhamento, pelos relatos de informantes, dos avanços e retrocessos de tais processos [..]. (VON SIMSON, 1999).

Foi utilizada uma entrevista semiestruturada direcionada, para melhor entendermos a maneira como a Capoeira foi introduzida nessa competição sob a perspectiva de modalidade esportiva, no intuito de responder o objetivo deste estudo. A escolha da entrevista justifica-se por sua abertura para expressão do sujeito da pesquisa e subjetividade nos dados finais. Desta forma, a coleta de dados aconteceu com o Mestre Marcos Antônio Gomes de Carvalho, responsável pela Capoeira no JERNs.

A entrevista aconteceu após a competição da categoria juvenil feminino, no dia 12 de outubro de 2015, no Centro de Atenção Integrada à Criança (CAIC), local de realização desta competição. Iniciamos com a explanação da pesquisa ao mestre e o convidamos para colaborar conosco.

Após a coleta dos dados, trabalhamos para dar uma unidade à narrativa dos fenômenos entre as falas e matérias de arquivo coletados.

\section{Cultura de movimento expresso na ginga do corpo}

Dialogando com o conceito de Cultura de Movimento proposto por Elenor Kunz, Mendes e Nóbrega (2009, p. 1) afirmam que esta

[...] ultrapassa a concepção de movimento humano reduzida a um fenômeno meramente físico, tido estritamente como um deslocamento do corpo no espaço, presente na visão de educação que o autor questiona. Ao considerar o ser humano que realiza o movimento, essa proposta passa a reconhecer as significações culturais e a intencionalidade do movimento humano. Para tanto, o autor problematiza a concepção mecanicista de corpo e de movimento, na qual o corpo está separado do mundo, buscando 
fundamentos na concepção fenomenológica de corpo e de movimento, ou seja, na ideia de que o ser humano é inseparável do mundo em que vive.

Partindo da ideia exposta acima, concordamos que o movimento não está apenas reduzido ao conjunto de reações biológicas, mas, também, de impressões culturais que nele interferem e o modificam. A capoeira, forte manifestação da cultura afro-brasileira e da cultura de movimento é resultado de um processo em que o meio interferiu de modo significativo em sua construção. Ou seja, as marcas e os saberes de cada povo estão imbricadas nas suas formas de mover-se e vice-versa. Com essa clareza sobre o entrelaçamento entre o meio e o corpo é possível perceber em cada gesto e em cada movimento da capoeira as características de sua origem.

Adicionalmente, a capoeira possui uma significação polissêmica, podendo ser atribuída de acordo com o contexto, sua essência e seu descompromisso com o rígido. Uma expressão cultural carregada de histórias, trazendo consigo uma característica única e bastante particular. Mello $(2002$, p. 1) caracteriza a capoeira como sendo:

uma manifestação cultural afro-brasileira criada pelos negros escravos como forma de luta contra a opressão, luta esta que se travou no plano físico e cultural. Em seu universo simbólico e motor encontramos elementos, tais como a musicalidade, a religiosidade, movimentos acrobáticos, dentre outros, que a tornam bastante peculiar. A capoeira é plural, e nela o lúdico e o combativo interpenetram-se, caracterizando-a como jogo, luta e dança.

A capoeira sofre ressignificações ao longo dos anos de acordo com os interesses sociais de cada época. Sua pluralidade diz respeito a muitas coisas, perpassando pela história chegando à gestualidade em si e o que isso expressa sobre o praticante e/ou a determinada cultura. Assim, corroboramos com as ideias de Nunes Dias (2010), que afirma que a gestualidade na capoeira não é apenas um ato mecânico, desprovido de intencionalidades, mas sim uma experiência na qual o sujeito atribui um sentido e reconhece isso no outro. "É enquanto duplo que articulamo-nos, reconhecendo nossos gestos, compartilhando nossas intencionalidades, estabelecendo relações intersubjetivas, reconstruindo constantemente a cultura" (NUNES DIAS, 2010, p. 5).

De modo suplementar, a capoeira, com sua riqueza cultural intrinsecamente ligada a diversos momentos de repressão e superação, gera um leque de possibilidades que nos permite explorá-la em suas diversas dimensões, condensando-a no jogo e seus aspectos lúdicos, na luta com a oposição dos corpos e o respeito mútuo, como na dança e seus elementos rítmicos ou até mesmo em sua dimensão esportiva, aproximando-se desta dimensão quando tem suas regras adaptadas para atender aos moldes esportivos exigidos a partir de sua inserção em campeonatos.

Esta imersão em sua dimensão esportiva pode nos permitir compreender a capoeira no contexto competitivo, ainda que de maneira subjetiva. Se pensarmos nos Conexões: Educ. Fís., Esporte e Saúde, Campinas: SP, v. 15, n. 2, p. 129-141, abr./jun. 2017. ISSN: 1980-9030 
eventos competitivos de capoeira existentes, observaremos que são pautados em regras próprias, baseados nas suas tradições e rituais. Universalizar suas regras, estilos, tradições, como propõe a instituição do esporte, é desconsiderar toda história desta manifestação. No entanto, entendemos que a subjetividade e as particularidades presentes nestas competições contribuem para que ela não perca sua legitimidade.

\section{A capoeira nos jogos escolares do Rio Grande do Norte}

Para discutir a Capoeira e suas relações com o contexto educacional no Rio Grande do Norte, optamos por resgatar sua história para entender como esta foi introduzida nos Jogos Escolares do Rio Grande do Norte (JERNs) como modalidade esportiva, na tentativa de responder nosso objetivo. Para isto, realizou-se uma entrevista semiestruturada com Marcos Antônio Gomes de Carvalho, o "Mestre Marcos", referência da Capoeira Angola no estado do Rio Grande do Norte e organizador geral da modalidade no JERNs.

A entrevista com o Mestre foi pensada devido o déficit de material acadêmico e de registro na Coordenadoria de Desportos do Rio Grande do Norte (CODESP), vinculada à Secretaria de Educação e da Cultura, órgão que organiza os JERNs, sobre a historicidade da Capoeira nesse evento, bem como sanar e registrar os percursos da Capoeira como modalidade esportiva no estado do RN. Portanto, este levantamento caracteriza-se como um estudo de caráter historiográfico por reescrever parte da memória de um indivíduo sobre determinado assunto. Por esta característica, fazemos uma ressalva na confiabilidade dos dados, pois a fonte oral "é uma construção que o indivíduo faz de seu passado com base nas experiências guardadas" (SELAU, 2004, p. 218).

Ao ser questionado sobre a introdução da Capoeira no JERNs, Mestre Marcos nos faz um levantamento histórico sobre os caminhos percorridos por essa modalidade em outras competições em nível nacional e como isto influenciou no ingresso desta nos Jogos Escolares do RN:

Olha, em 1985 houve uma corrente no Ministério da Educação onde se trabalhava os esportes de identidade cultural: os esportes indígenas, a cultura afro; então houve uma proposta de introduzir a capoeira nos Jogos Escolares Brasileiros, o que hoje são os jogos da Juventude. E a capoeira entrou em 1985, com base numa regulamentação da confederação brasileira de pugilismo, que por sinal e dentro do seu foco de estudo, não se tem notícia que as mulheres participavam, naquela época da confederação brasileira de pugilismo (MESTRE MARCOS, 2015).

É possível localizar na fala do entrevistado uma leitura do movimento mais amplo pelo qual o esporte educacional estava passando no cenário nacional, pois, segundo Correio, Bortoleto e Paoliello (2012) a inclusão da Capoeira nos Jogos Escolares Brasileiros (JEBs) aconteceu após a mudança da comissão organizadora do 
evento, que alterou o objetivo central desses jogos, antes marcado pela exaltação do desempenho esportivo dos alunos. Nessa transição dos administradores, tem-se o intuito de valorizar os Jogos como evento educacional. A fala do Mestre Marcos também coaduna com os registros que relatam que "a primeira tentativa de competição de capoeira foi organizada pela Confederação Brasileira de Pugilismo (CBP), em 1985" (CORREIO, 2012, p. 278).

Nesse contexto, percebe-se que a Capoeira foi pensada pelo Ministério da Educação, no ano de 1985, como esporte ou modalidade que transpassa as questões culturais, já indicando uma relação com a cultura brasileira e sua importância educacional. No entanto, só em 2008 a Roda de Capoeira foi inscrita no livro de Registro das Formas de Expressão, bem como o Ofício ao Mestre de Capoeira no livro dos Saberes reconhecido pelo Instituto do Patrimônio Histórico e Artístico Nacional, órgão do Ministério da Cultura (IPHAN/MinC) como Patrimônio Imaterial da Humanidade (BRASIL, 2014).

Considerando a competição na capoeira um campo muito recente, questionamos ao entrevistado como se deu o processo de criação dos regulamentos desenvolvidos para reger esses eventos de caráter competitivo. Mestre Marcos inicialmente afirma que os estados brasileiros costumavam desconsiderar as características ritualísticas e culturais da Capoeira, considerando-a apenas em sua dimensão de luta

Quando entrou nos jogos escolares em 85 houve muita agressividade, violência e esse desvio nas características culturais da capoeira. [...] aí o regulamento foi contestado porque ameaçaram retirar a capoeira por conta de algumas atitudes de violência, agressividade e nós passamos a semana tentando ajustar esse regulamento para uma forma que pudesse preservar as características culturais e ter essa experiência da capoeira como esporte competição. 86,87 aí foi se firmando essa nova forma de ver, de introduzir a capoeira e foi sendo feita essa experiência. (MESTRE MARCOS, 2015).

É possível perceber no discurso acima mencionado que na ocasião de ingresso da capoeira nos Jogos Escolares a agressividade, mascarada como luta, esteve tão enfatizada que causou dúvidas quanto a sua permanência nesse evento de cunho desportivo e educativo. Estabelecendo relações com as primícias da capoeira, podemos associar essa maior inclinação à luta devido aos vários anos que essa manifestação teve que assumir, tornando-se mais rígida. Podemos considerar também que esse afastamento do viés cultural da capoeira para transformá-la ou transpô-la ao universo competitivo tenha se dado pelas referências de outras lutas já consolidadas nesse campo, como o pugilismo, onde os ataques e defesas ocorrem de forma mais clara. 
Criada em um contexto de opressão, essa manifestação da cultura de movimento necessitou, durante muito tempo, desenvolver no corpo elementos de defesa e ataque, enfatizando e perpetuando as características de capoeira como luta. Com isso, as impressões permanecem intensas na forma de jogar dos capoeiristas. Pensando no entrelaçamento entre corpo e cultura, consequentemente nas marcas socioculturais deixadas nas manifestações da cultura de movimento e na capoeira como uma dessas possibilidades, é possível considerar que

[...] o gesto possui um sentido, uma direção, compõe uma diversidade de significações, nos diferentes contextos desenhados pela gestualidade do corpo, caracterizando uma relação sempre original com o mundo. (NUNES DIAS, 2010, p. 620).

Corroborando com esse pensamento, podemos nos reportar à ideia de técnicas corporais, ou seja, "as maneiras pelas quais os homens, de sociedade a sociedade, de uma forma tradicional, sabem servir-se de seu corpo" (MAUSS, 2003, p. 401), em que os elementos sociais, psicológicos e biológicos estão indissoluvelmente misturados. Nesse sentido é possível perceber que o manejo do corpo e, consequentemente, de suas técnicas utilizadas pela capoeira foi sendo determinada a partir dos limites e das possibilidades que esta prática obteve para se manter.

Nesses movimentos de se reinventar e para se firmar no contexto de esporte de competição, a capoeira precisava ser considerada também pelas suas particularidades culturais e não apenas como luta. Com a intenção de abranger a capoeira em sua totalidade, Mestre Marcos traz a proposta para o estado do Rio Grande do Norte para introduzi-la nos eventos de competições escolares “[...] eu levei a proposta para a CODESP, [...] eles me deram a oportunidade e nós fizemos um festival e [eles] gostaram. Então, a partir de 87 a experiência vem se repetindo e ganhando todas as áreas, todos os níveis do desporto escolar no estado" (MESTRE MARCOS, 2015).

Com a conquista dos espaços de competições estudantis do estado, a Capoeira está presente não apenas nos Jogos Escolares do Rio Grande do Norte (JERNs), mas também no JERNINHOS (para os alunos menores de 11 anos, idade mínima para participar dos JERNs), no Campeonato das Escolas Estaduais e Municipais (CEEMs) e nos Jogos Escolares de Mossoró (JEMs). Com essa leitura da implantação da Capoeira nos jogos escolares no estado do Rio Grande do Norte e não apenas a nível nacional, questionamos sobre a presença desse esporte nos demais estados brasileiros e Mestre Marcos afirma:

Não se tem notícia de outro estado ter continuado porque a experiência de jogos escolares brasileiros veio até 95 e por um motivo, uma corrente que entendeu que se complicavam, houve um problema no INDESP com um grupo de capoeira e verba pra capoeira, a partir de lá saiu acabou os jogos escolares, que foi transformado jogos escolares brasileiros em jogos da juventude e a 
capoeira não foi contemplada de prosseguir a experiência (MESTRE MARCOS, 2015).

Percebe-se que, apesar da retirada da Capoeira dos Jogos Escolares Brasileiros (JEBs), houve uma contribuição significativa dessa experiência para o estado do Rio Grande do Norte, pois além do incentivo para levá-la para os jogos estudantis do estado, os JEBs possibilitaram um modelo de organização de um evento competitivo, que não é tradição dessa manifestação, por ser múltipla e possuir conceitos que ultrapassam os limites da definição de esporte.

Um marco nas competições dos JEBs aconteceu em 1987, quando os árbitros que valorizam a performance foram substituídos pelos Mestres de Capoeira, que visavam um esporte educacional. Sobre o modelo de competição, sabe-se que existiam cinco momentos, a saber: $1^{\circ}$ roda - jogo ao som de São Bento Grande da Regional $^{2}$ e São Bento Pequeno da Angola $^{3} ; 2^{\circ}$ ) coreografia - apresentações em equipe; $3^{\circ}$ ) concurso de ladainha ${ }^{4} ; 4^{\circ}$ ) seminário - um trabalho para cada equipe e $5^{\circ}$ ) a conferência com os mestres, mudando para oficina prática com os mestres no ano de 1989.

Atentando para a Capoeira em sua pluralidade, e não apenas como esporte que demande uma performance física, os Jogos Escolares do Rio Grande do Norte estão organizados "Em quatro modalidades, pensando no jogo, enquanto jogo com o colega de outra escola. Enquanto uma harmonia e criatividade na dupla; pesquisa e investigação sobre essa reflexão sobre a capoeira e a parte mais musical ou poética que é a ladainha" (MESTRE MARCOS, 2015). Destaca-se ainda que essa organização abrange mais do que a dimensão esportiva da Capoeira, pois explora seu lado artístico e estético, bem como a estimulação da pesquisa sobre a cultura afrobrasileira pelos alunos.

Ao ser questionado sobre a importância da Capoeira nos Jogos Escolares do Rio Grande do Norte, Mestre Marcos nos faz apontamentos de uma Capoeira que educa por excelência, arte que alcança em diversas dimensões o elo com a educação, com a cultura, além do seu aspecto esportivo, considerando sua presença nos JERNs. Mestre Marcos deixa isso evidente ao afirmar que:

É importante porque a dimensão educativa da capoeira ela se acentua e passa a ser observada com mais cuidado, mais detalhes e os professores de capoeira se veem numa missão de educador e a capoeira com a escola da capoeira, porque a capoeira tem uma escola própria de fundamento, de respeito, de formação durante toda essa história do Brasil. Ela esteve presente no movimento de reivindicação de igualdade social, de resistência cultural, guerra do

\footnotetext{
2 Também conhecido como São Bento Grande de Bimba, é um toque específico da Capoeira Regional e rege o ritmo a ser jogado. Possui características veloz, que propõe um jogo mais rápido e objetivo.

3 Toque específico da Capoeira Angola, possui características de um jogo mais lento e cadenciado.

${ }^{4}$ A ladainha são os cânticos, sendo mais tradicionais na Capoeira Angola, portanto possuem um ritmo lento e que conta, geralmente, uma história. Essa competição propõe ao atleta desenvolver sua criatividade elaborando músicas inéditas.

Conexões: Educ. Fís., Esporte e Saúde, Campinas: SP, v. 15, n. 2, p. 129-141, abr./jun. 2017. ISSN: 1980-9030
} 
Paraguai, na revolta das chibatas, em todas essas dificuldades da sociedade brasileira a capoeira foi uma cultura muito presente e continua sendo agora quando a educação brasileira busca novos caminhos, com a educação integral, com os programas Mais Educação, que tem levado a capoeira pra escola, então essa possibilidade do esporte, da capoeira esportiva, cultural contemplada junto com a educação tanto favorece a capoeira como a própria educação que precisa de uma renovação na escola, uma escola mais viva, uma escola mais alegre, uma escola que tenha identidade cultural que tenha a cara dos nossos jovens e das nossas crianças.

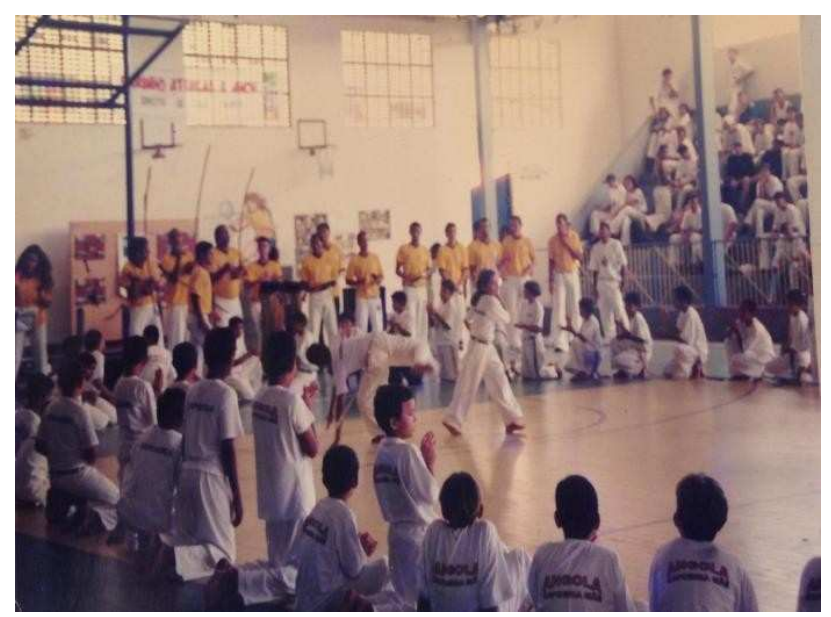

Figura 1 - JERNs 2000 - Contemporâneo.

Fonte: Acervo pessoal do Mestre Marcos.

Relembrando os entraves históricos vividos pela Capoeira e suas conquistas ao longo dos anos, podemos observar que, para o Mestre Marcos, a importância da desse esporte nos JERNs está pautada no incentivo aos professores da modalidade em específico e na divulgação dessa arte à comunidade em geral, mostrando seus valores e as adequações que essa manifestação da cultura de movimento teve que passar para manter-se viva.

Ainda sobre esse movimento de avanços e conquistas da Capoeira, o Mestre discorre sobre o crescimento da participação feminina em todas as competições escolares do Rio Grande do Norte, considerando que por muito tempo a representatividade da mulher era baixa em relação aos homens e ela era excluída, "embora houvesse no passado presença de mulheres dentro da capoeira, pra ter ideia os apelidos das mulheres era "Maria doze homens". Mestre Marcos (2015), reafirmando a incorporação do que é considerado masculino para ser legitimar nesse espaço de pouca abertura às mulheres. Mestre Marcos ainda diz que os Jogos Escolares do Rio Grande do Norte são uma possibilidade de conquistar as mulheres para a prática da Capoeira. 


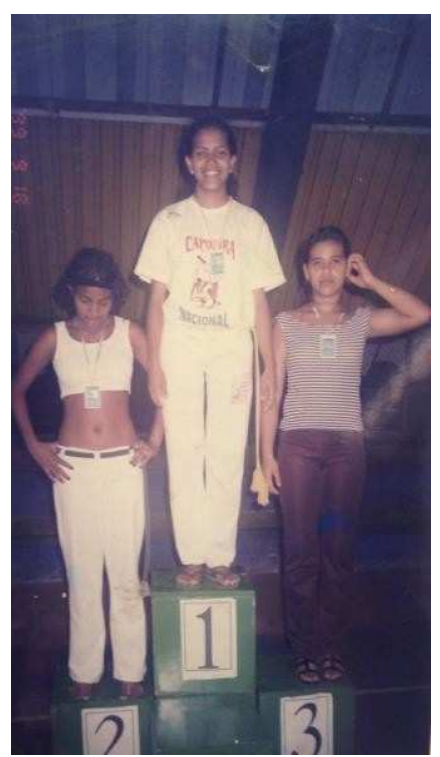

Figura 2 - Pódio feminino JERNs CAIC.

Fonte: Acervo pessoal do Mestre Marcos.

\section{Conclusão}

A partir da narrativa do Mestre Marcos, percebemos que o estado do Rio Grande do Norte baseou-se em competições como os Jogos Escolares Brasileiros, evento que disseminou a Capoeira como esporte-competição a todo Brasil, mas que não se consolidou nesse espaço por interesses políticos. Contudo, à revelia do insucesso na dimensão nacional, o Estado do Rio Grande do Norte conseguiu organizar-se em função de um espaço de visibilidade que, apesar de esportivo, dialoga com as singularidades culturais e de expressão da manifestação da capoeira, segundo nosso informante. Consideramos a relevância desta narrativa como forma de registro e disseminação dos fatos sobre uma história que não é contada por documentos oficiais à disposição da sociedade. Ao narrar sobre a Capoeira no estado do RN e seus aspectos educacionais, Mestre Marcos nos brinda com uma forma dialogada e interessante de competição que estabelece nexos entre a codificação de um evento esportivo e o respeito à lógica de expressão da arte capoeira.

Entendemos que conhecer sobre a historicidade da capoeira no JERNs e como essa manifestação vem sendo constituída como esporte-competição se fez necessário para compreender e registrar estes dados, além de apontar caminhos para pesquisas futuras ampliando esses olhares diante da Capoeira e de deixar legados da pesquisa no centro de memória em esporte e lazer do Rio Grande do Norte, servindo como referência para a sociedade, considerando que são dados insipientes na literatura e na memória do estado, de forma mais ampla.

Destacamos, portanto, que para alcançar uma visão mais ampliada sobre essa temática se faz necessário ouvir outros sujeitos participantes dessa história, uma vez que 
as informações aqui apresentadas foram disponibilizadas pelo próprio organizador do evento. Assim, poderíamos ter uma compreensão mais ampla sobre a introdução da capoeira como esporte-competição no contexto dos Jogos Escolares, considerando.

Estamos satisfeitos com a realização da pesquisa, apesar de compreender que fizemos apenas um recorte a partir da narrativa do Mestre Marcos. O caminho metodológico que escolhemos seguir nos possibilitou compreender, pela ótica do entrevistado, como a Capoeira foi historicamente constituída nos espaços estudantis do RN, especificamente nos Jogos Escolares do Rio Grande do Norte.

\section{REFERÊNCIAS}

BRASIL. Ministério da Cultura. Instituto do Patrimônio Histórico e Artístico Nacional. Roda de capoeira. [2014?]. Disponível em:

<http://portal.iphan.gov.br/pagina/detalhes/66>. Acesso em: 20 abr. 2015.

BRASIL. Ministério do Esporte. Apresentação. [2008?]. Disponível em: <http://www2.esporte.gov.br/sndel/esporteLazer/cedes/apresentacao.jsp>. Acesso em: 08 abr. 2016.

CORREIO, Lívia de Paula Machado Pasqua; BORTOLETO, Marco Antônio Coelho; PAOLIELLO, Elizabeth. Competições de capoeira: apontamentos preliminares sobre os jogos regionais realizados pela FECAESP e pela abadácapoeira no estado de São Paulo. Pensar a Prática, Goiânia, v. 15, n. 2, p. 272-550, 15 jun. 2012.

GIL, Antônio Carlos. Métodos e técnicas de pesquisa social. 6. ed. São Paulo: Atlas, 2008 .

MAUSS, Marcel. Sociologia e antropologia. São Paulo: Cosac Naify, 2003.

MELLO, André Silva. A história da capoeira: pressuposto para uma abordagem na perspectiva da cultura corporal. In: CONGRESSO BRASILEIRO DE HISTÓRIA DA EDUCAÇÃO FÍSICA, ESPORTE, LAZER E DANÇA, 8., 2002, Ponta Grossa. Anais... Ponta Grossa: Universidade Estadual de Ponta Grossa, 2002.

MENDES, Maria Isabel Brandão de Souza; NÓBREGA, Terezinha Petrucia da. Cultura de movimento: reflexões a partir da relação entre corpo, natureza e cultura. Pensar a Prática, Goiânia, v. 12, n. 2, p.1-7, jul. 2009.

NUNES DIAS, João Carlos Neves de Souza e. Narrativas do corpo e da gestualidade no jogo da capoeira. Motriz, Rio Claro, v. 16, n. 3, p. 620-628, jul. 2010. 
REGO, Waldeloir. Capoeira Angola: ensaio sócio-etnográfico. Salvador: Itapuã, 1968.

SELAU, Mauricio da Silva. História oral: uma metodologia para o trabalho com fontes orais. Esboços: Revista do Programa de Pós-Graduação em História da UFSC, Florianópolis, v. 11, n. 11, p. pp. 217-228, jan. 2004. Disponível em:

<https://periodicos.ufsc.br/index.php/esbocos/article/view/486/9887>. Acesso em: 28 out. 2016.

VON SIMSON, Olga R. de Moraes. Folguedo carnavalesco, memória e identidade sócio-cultural. Resgate, Campinas, n. 3, 1999. 

ERROR: syntaxerror

OFFENDING COMMAND: --nostringval--

\section{STACK :}

/ Title

()

/ Subject

(D:20170814161115-03'00')

/ModDate

( )

/Keywords

(PDFCreator Version 0.9.5)

/Creator

(D:20170814161115-03'00')

/CreationDate

(dulce)

/Author

-mark- 